Sharif University of Technology
Scientia Iranica
SCIENTIA
I RAN I CA
http://scientiairanica.sharif.edu

\title{
Evaluation of shear strength parameters of granulated waste rubber using artificial neural networks and group method of data handling
}

\author{
D. Rezazadeh Eidgahee ${ }^{a}$ A. Haddad ${ }^{a, *}$, and H. Naderpour ${ }^{b}$ \\ a. Geotechnical Engineering, Faculty of Civil Engineering, Semnan University, Semnan, Iran. \\ b. Structural Engineering, Faculty of Civil Engineering, Semnan University, Semnan, Iran. \\ Received 28 November 2017; received in revised form 13 January 2018; accepted 5 February 2018
}

\author{
KEYWORDS \\ Rubber materials; \\ Size effect; \\ Shear strength; \\ Vertical strain; \\ Direct Shear Test \\ (DST); \\ Artificial Neural \\ Network (ANN); \\ Group Method \\ of Data Handling \\ (GMDH); \\ Combinatorial \\ (COMBI).
}

\begin{abstract}
Utilizing rubber shreds in the civil engineering industry, such as geotechnical structures, can accelerate the generated waste tire recycling process in an economic and environmentally-friendly manner. However, understanding the strength parameters of rubber grains is required for engineering designs and can be acquired through experimental tests. In this study, small and large direct shear tests were implemented to specify shear strength parameters of five groups of rubber grains, which are different in gradation and size. Moreover, Artificial Neural Networks (ANN) were developed based on the test results, and optimized networks, which best captured the shear stress $(\tau)$ and vertical strain $\left(\varepsilon_{v}\right)$ behavior of rubbers, were introduced. Additionally, a prediction model using the combinatorial algorithm in Group Method of Data Handling (GMDH) was proposed for the shear strength and vertical strain in the arrangement of closed-form equations. The performance and accuracy of the proposed models were checked using correlation coefficient $(R)$ between the experimental and predicted data, and the existing Mean Square Error (MSE) was evaluated. $R$-values of the modeled $\tau$ and $\varepsilon_{v}$ were found to be equal to 0.9977 and 0.9994 for ANN and 0.9862 and 0.9942 for GMDH models, respectively. The GMDH proposed models were presented as comparatively simple explicit mathematical equations for further applications.

(C) 2019 Sharif University of Technology. All rights reserved.
\end{abstract}

\section{Introduction}

The increase of rubber wastes has become a thoughtful environmental problem, particularly in the form of used tires due to the industrial life and population growth. The recycling process of used tires and rubbermade materials is the main problem associated with the

\footnotetext{
*. Corresponding author.

E-mail addresses: d.rezazade@semnan.ac.ir (D. Rezazadeh Eidgahee); ahadad@semnan.ac.ir (A. Haddad); Naderpour@semnan.ac.ir (H. Naderpour)
}

complex structure and composition of rubber materials. Based on the available statistics, millions of tire wastes are being discarded every year all around the world [13]. Sustainable development might become possible through the management of used tires and rubber materials by grinding them and the reuse of obtained materials in this process in the form of granulated rubbers as a component or filler. These materials can be considered environmentally friendly and economically efficient if they can be reused in industries such as civil engineering.

Furthermore, rubber materials must have some particular features in order to be suitably used in geotechnical applications. Different researchers have 
Table 1. Summary of some previous studies on rubber grains shear strength resulting from direct shear testing.

\begin{tabular}{|c|c|c|c|c|c|c|}
\hline Research & $\begin{array}{c}\text { Direct shear } \\
\text { test type }\end{array}$ & $\begin{array}{l}\text { Maximum grain } \\
\text { size }(\mathrm{mm})\end{array}$ & $\begin{array}{c}\sigma_{n} \\
(\mathbf{k P a})\end{array}$ & $\begin{array}{c}c \\
(\mathrm{kPa})\end{array}$ & $\begin{array}{c}\varphi \\
\text { (degree) }\end{array}$ & $\begin{array}{c}\text { Failure criterion } \\
\text { point }\end{array}$ \\
\hline \multirow{3}{*}{ Humphery et al. (1993) [4] } & \multirow{3}{*}{ Large scale } & 51 & $17-68$ & 7.7 & 21 & \multirow{3}{*}{ Peak or at $10 \%$ disp. $^{\mathrm{b}}$} \\
\hline & & 76 & $17-63$ & 11.5 & 19 & \\
\hline & & 38 & $17-62$ & 8.6 & 25 & \\
\hline Foose et al. (1996) [20] & Large scale & $50,100,150$ & $1-76$ & 3 & 30 & Peak or at $9 \%$ disp. ${ }^{b}$ \\
\hline Gebhardt (1997) [28] & Large scale & 1400 & $5.5-28$ & 0 & 38 & $10 \%$ disp. \\
\hline Yang et al. (2002) [6] & Small scale & 10 & $0-83$ & 0 & 32 & $10 \%$ disp. \\
\hline Fox et al. (2018) [30] & Large scale & 320 & 76.7 & $\mathrm{NA}^{\mathrm{a}}$ & 30.2 & $13 \%$ disp. \\
\hline
\end{tabular}

${ }^{a}$ NA means that the data were not achievable through the corresponding reference.

${ }^{\mathrm{b}}$ The failure was considered to be the peak shear stress. If no peak was reached, the shear at a horizontal

displacement equal to 10,9 , and $15 \%$ of the length of the shear box was taken.

demonstrated the proficient use of rubber wastes in different purposes such as retaining wall backfills [4], road embankments [5], subsurface drainage systems and buried pipeline trenches [6,7], and landfill leachates [8]. Additionally, shredded rubber masses solely or in the form of a mixture with sand can be used as an aggregate replacement in the highway construction; they were supposed to be designed for flexible pavement structures in particular $[5,9,10]$. Structures that are utilizing shredded scrap tires should, however, be designed to minimize the potential for internal heating and combustion [11]. The guidelines presented in ASTM D6270 [12] for the use of tire scraps in civil engineering applications should be followed to minimize the aforementioned risk.

The use of rubber materials in geotechnical structures requires understanding the mechanical behavior and engineering properties of such materials, among which shear strength characteristics are the most important and common criteria. The properties of tire wastes, such as durability, strength, resiliency, and high frictional resistance, are the most significant parameters to consider in the design of highway embankments [13]. Experimental tests have been performed by many researchers on the soil-rubber mixture to determine the most efficient fraction of the blend for which the shear strength parameters have maximum values and to improve geotechnical properties of the soil alone [14-26]. However, rubber shred masses can be used to act like sand and gravel grains in a lightweight and more compressible manner [27]. Conducted tests on rubber grains ranged in size from 10 to $1400 \mathrm{~mm}$, and reported friction angles varied from 19 to 38 degrees with the cohesion intercept of 0 to $11.5 \mathrm{kPa}$ at normal stresses between 0 and $83 \mathrm{kPa}[20,28,29]$. Moreover, large tire derived aggregates ranging in size between 30 and $300 \mathrm{~mm}$ were tested using a novel largescale direct shear device [30].

By implementing different grinding techniques, various rubber grain sizes and shapes that have different mechanical properties and shear strengths can be obtained [12]. Table 1 summarizes previous studies on the shear strength parameters of rubber material grains, resulting from the Direct Shear Test (DST). However, the effect of gradation and factors involved in particle size distribution, such as uniformity and curvature coefficients, are not discussed.

Former researchers have shown evidence of the practical effect of gradation and grain size for design purposes $[15,21,31]$. The objective of this paper is to investigate the effect of particle-size distribution of rubber grains on shear strength parameters through an experimental study on five different gradations. Furthermore, by using Direct Shear Tests (DST) results, Artificial Neural Network (ANN) and Group Method of Data Handling (GMDH) are implemented for proving a general prediction model of rubber material shear stress-strain behavior further in this research.

\section{Materials and methods}

\subsection{Materials}

According to the particle size distribution of rubber materials, five different gradations were used in this study, none of which contained steel wires, nylon, or synthetic fibers. Grain sizes varied in the range of 0.075 to $4.75 \mathrm{~mm}$, and the specific gravity test resulted in an average value of 1.13 (between 1.10 and 1.16), which is consistent with those reported in ASTM D6270 for various tire shreds and tire chips (varying from 1.02 to 1.27 with an average value of 1.15). The recommendations of ASTM D6270 were generally followed in this study. Granulated rubber sets, GR1 and GR3, contain particles varying in diameter from 0.075 to $1.18 \mathrm{~mm}$ and 0.425 to $4.75 \mathrm{~mm}$, respectively, and GR2 is widely distributed between the other two with grains' diameters between 0.075 and $4.75 \mathrm{~mm}$. Based on the Unified Soil Classification 


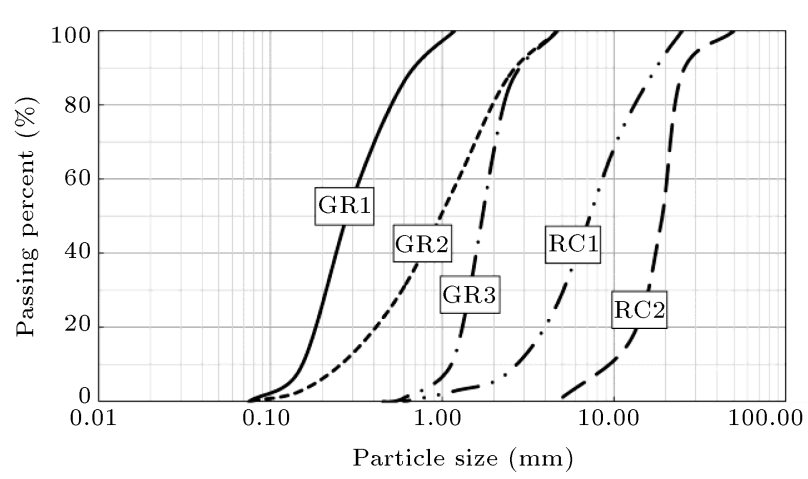

Figure 1. Particle size distribution of rubber materials.

Table 2. Rubber samples particle distribution characteristics.

\begin{tabular}{cccccc}
\hline & \multicolumn{5}{c}{ Rubber samples } \\
\cline { 2 - 6 } Parameter & GR1 & GR2 & GR3 & RC1 & RC2 \\
\hline$D_{50}$ & 0.28 & 0.97 & 1.71 & 7.50 & 19.10 \\
$C_{u}$ & 2.20 & 5.00 & 1.61 & 3.22 & 2.03 \\
$C_{c}$ & 0.89 & 1.08 & 0.99 & 1.15 & 1.23 \\
\hline
\end{tabular}

System (USCS) and according to ASTM D2487 [32], all the specimens were categorized as poorly graded sand (SP). Additionally, two other groups of rubber samples, $\mathrm{RC} 1$, and RC2, were classified as poorly graded gravels (GP), for which the rubber chips label was selected based on ASTM D6270 recommendations [12]. Particle size distributions of the samples are shown in Figure 1. It is obvious that GR1, GR3, and RC2 are uniformly distributed, while GR2 and RC1 are extended between them to provide a wide distribution. In addition, uniformity coefficient $\left(C_{u}\right)$, curvature coefficient $\left(C_{c}\right)$, and mean size $\left(D_{50}\right)$ are presented in Table 2 for each specimen.

\subsection{Methods}

\subsubsection{Testing}

For GR samples, small direct shear test apparatus was performed which has a square specimen box (mold) with the side size of $100 \mathrm{~mm}$. The initial thickness of all samples was $30 \mathrm{~mm}$ placed in the shear box by three $10 \mathrm{~mm}$ layers. However, for RC samples, the large direct shear test was used in which the side size of a square sample box is $300 \mathrm{~mm}$ and its depth is $150 \mathrm{~mm}$. RC samples were prepared in 5 layers of $30 \mathrm{~mm}$ thickness. Horizontal displacement rate was set to $0.5 \mathrm{~mm}$ per minute in order to perform shear tests on rubber samples. The mold was greased to reduce the wall-particle friction effect and to ensure that it has no effect on the shearing plane. The tests were performed based on the procedure described in ASTM D3080 [33], and five different normal stresses $\left(\sigma_{n}\right)$ of $5,25,50,100$, and $150 \mathrm{kPa}$ were applied.

The results achieved through direct shear test- ing include shear stress $(\tau)$ and vertical strain $\left(\varepsilon_{v}\right)$ responses, which are changing with horizontal strain $\left(\varepsilon_{h}\right)$ for the samples. Figures 2-6 depict $\tau$ and $\varepsilon_{v}$ changes versus $\varepsilon_{h}$. Of note, due to the fact that none of the shear stress curves has well-defined peaks, failure criteria were chosen at 15 and 12 percent of horizontal strain for GR and RC samples, respectively, performed using 10 and $30 \mathrm{~cm}$ shear boxes, respectively. The same procedure of rubber material testing was reported by other researchers $[4,6,20,28]$. The shear strength parameters of samples were interpreted based on MohrCoulomb failure criteria in the form of cohesion intercept $(c)$ and internal friction angle $(\varphi)$.

\subsubsection{Data preprocessing}

In order to offer appropriate information for soft computing model development, DST test results on the rubber specimens were collected including 890 test result points. Five input parameters were selected based on their direct effect on the shear stress responses of the materials. Based on the acquired results, it can be concluded that the particle size distribution affected the shear stress and vertical strain responses. Moreover, the applied normal stress and the horizontal strain are two other variables in the direct shear test, directly affecting the results. Thus, input variables include normal stress $\left(\sigma_{n}\right)$, horizontal strain $\left(\varepsilon_{h}\right)$, uniformity coefficient $\left(C_{u}\right)$, and curvature coefficient $\left(C_{c}\right)$ and the dimension corresponding to 50 percent passing by weight $\left(D_{50}\right)$. The target values that form the responses of DST include shear stress $(\tau)$ and vertical strain $\left(\varepsilon_{v}\right)$, which can be presented versus horizontal strain $\left(\varepsilon_{h}\right)$. Input and target data statistical summaries are presented in Table 3 .

With the aim of avoiding a slow learning rate in soft computing model development, this study used the standardization function and scaling technique, thus converting values of each input parameter and experimentally measured value between 0.1 and 0.9 using the following equation:

$$
Y_{m}^{n}=0.8\left(\frac{X_{m}^{n}-X_{m, \min }}{X_{m, \max }-X_{m, \min }}\right)+0.1,
$$

where $Y_{m}^{n}$ is the normalized and scaled value of $X_{m}^{n}$ considered to be between 0.1 and $0.9, m$ is the $m$ th parameters involved in the model, and $n$ indicates the $n$th experimental value of the $m$ th parameter. Used data were randomly shuffled before any model development in order to provide more authentic models. In addition, zero values involved in the calculations were divided by zero while calculating relative values, especially in error estimation.

\subsubsection{ANN model development}

According to recent progressions in computational engineering and computer science, Artificial Neural 


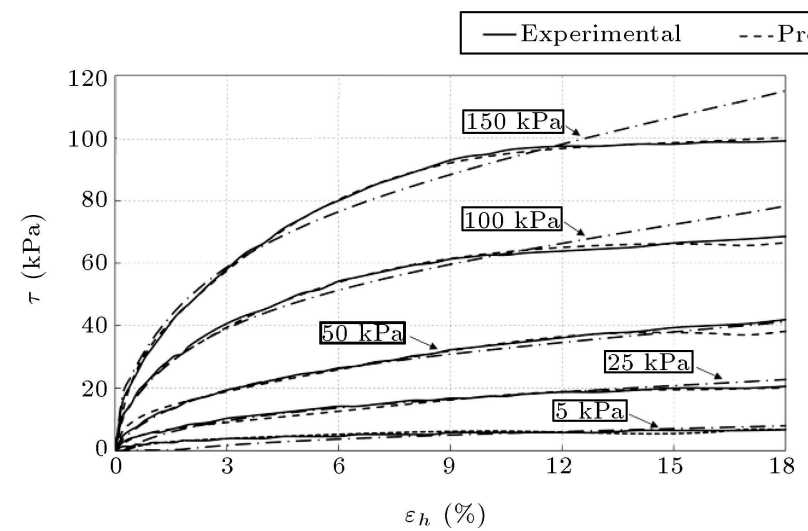

(a)

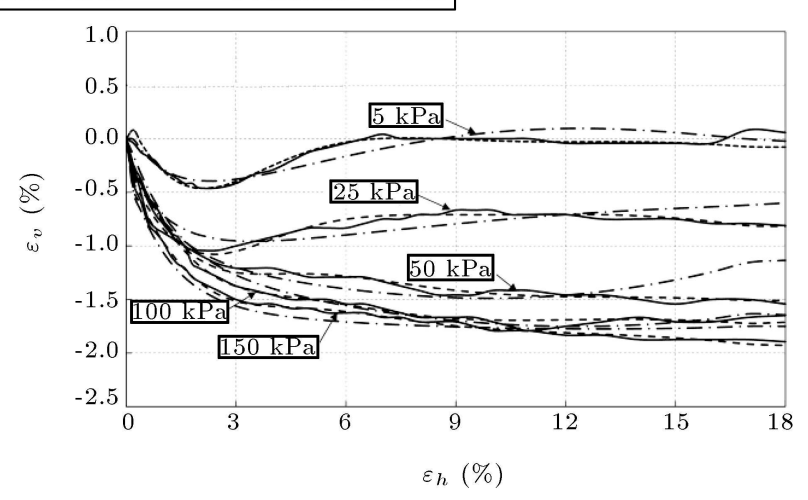

(b)

Figure 2. Direct shear test, ANN and GMDH results for GR1: (a) Shear stress and (b) vertical strain versus horizontal strain.

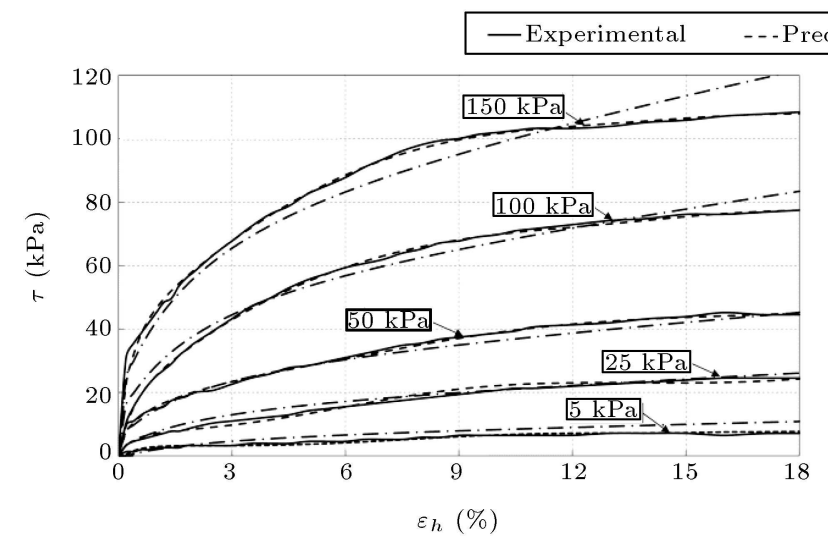

(a)

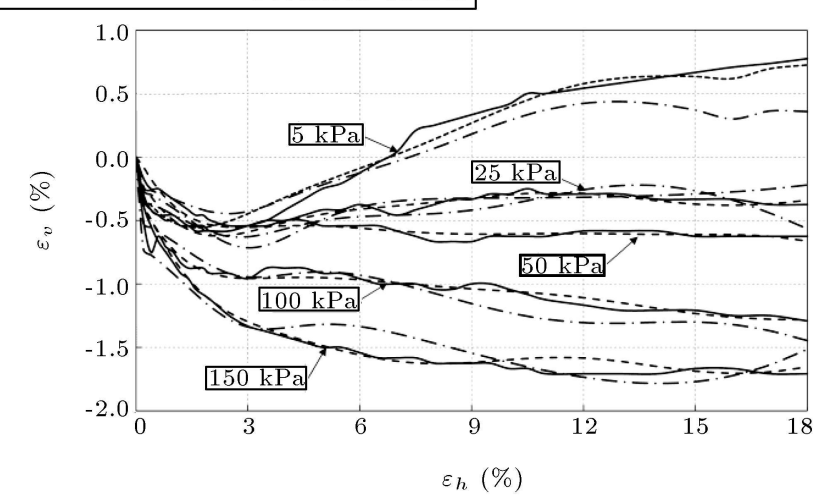

(b)

Figure 3. Direct shear test, ANN and GMDH results for GR2: (a) Shear stress and (b) vertical strain versus horizontal strain.

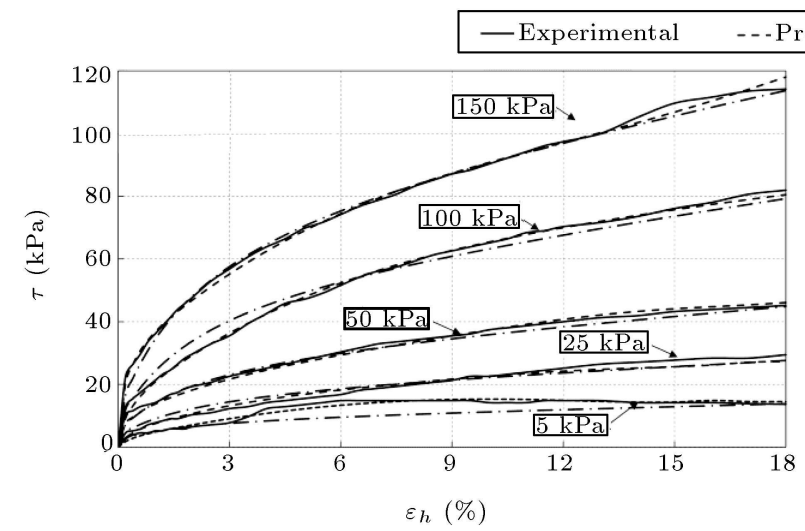

(a)

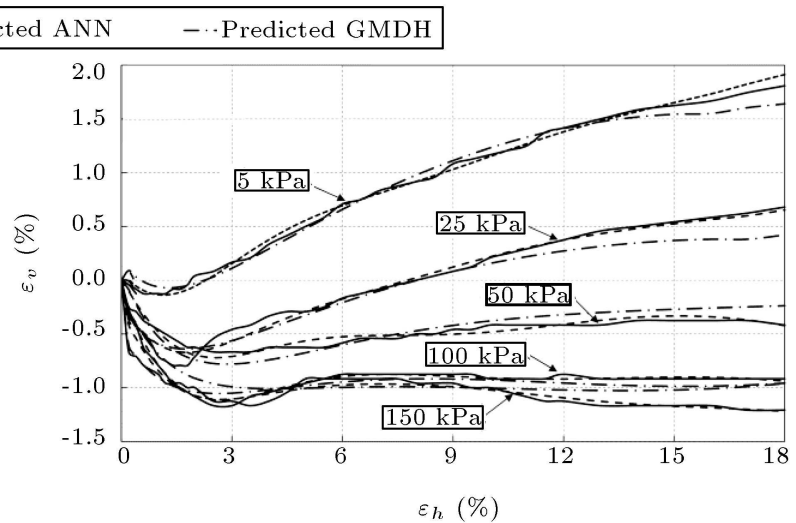

(b)

Figure 4. Direct shear test, ANN and GMDH results for GR3: (a) Shear stress and (b) vertical strain versus horizontal strain.

Networks (ANNs) have been widely adopted for modeling engineering problems. These methods were shown to be reliable to provide predictive models and, due to their data-driven basis, there is no requirement for preceding knowledge of the associations of the variables [34]. Thus, ANNs do not include any preprocessed equations and the models are trained in order to find the relationships that associate a group of selected inputs with their target values $[35,36]$.

This computational tool has been adopted from a 


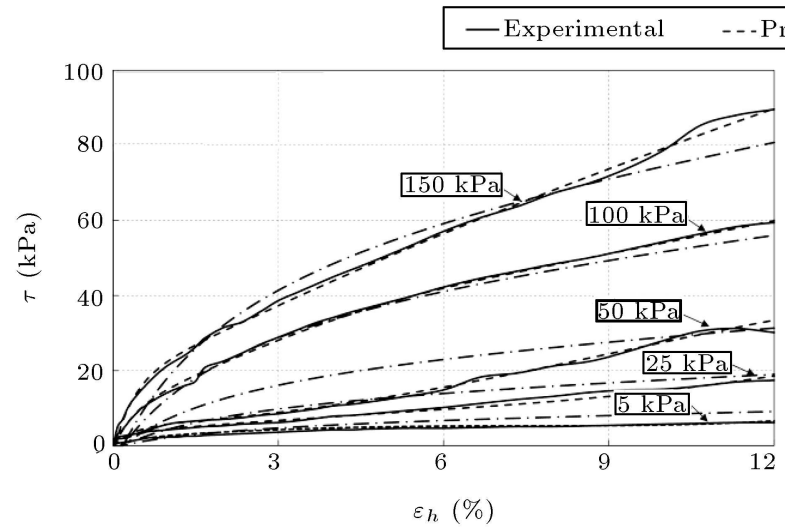

(a)

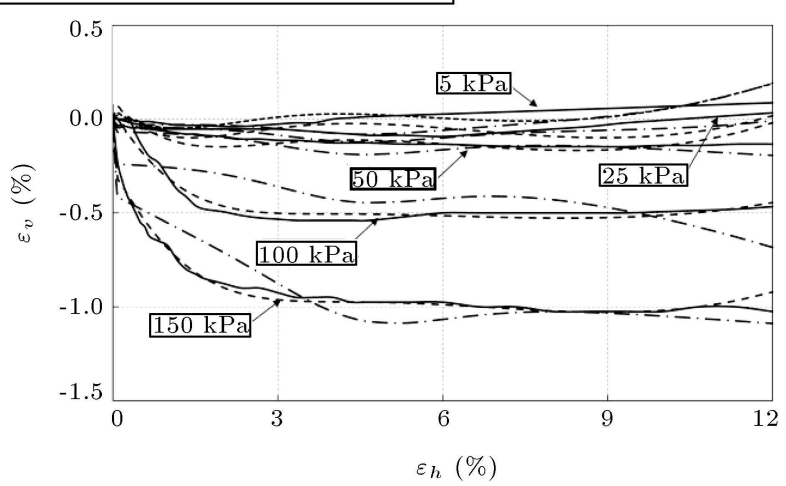

(b)

Figure 5. Direct shear test, ANN and GMDH results for RC1: (a) Shear stress and (b) vertical strain versus horizontal strain.

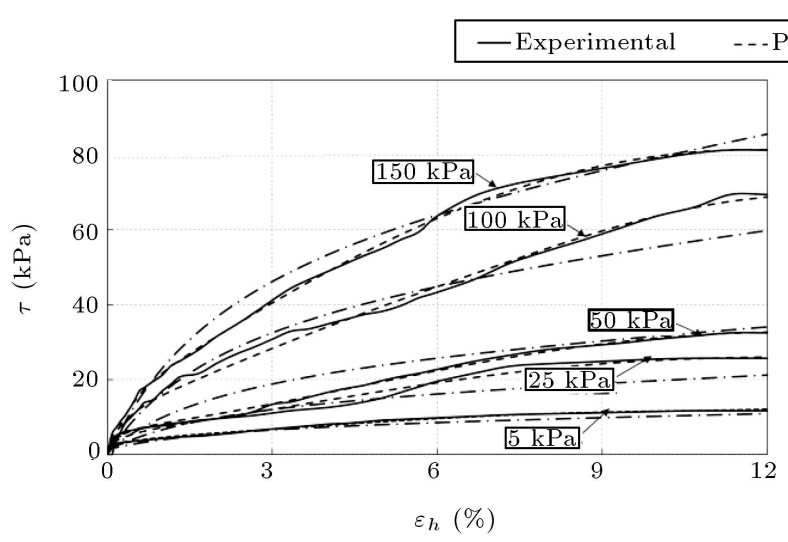

(a)

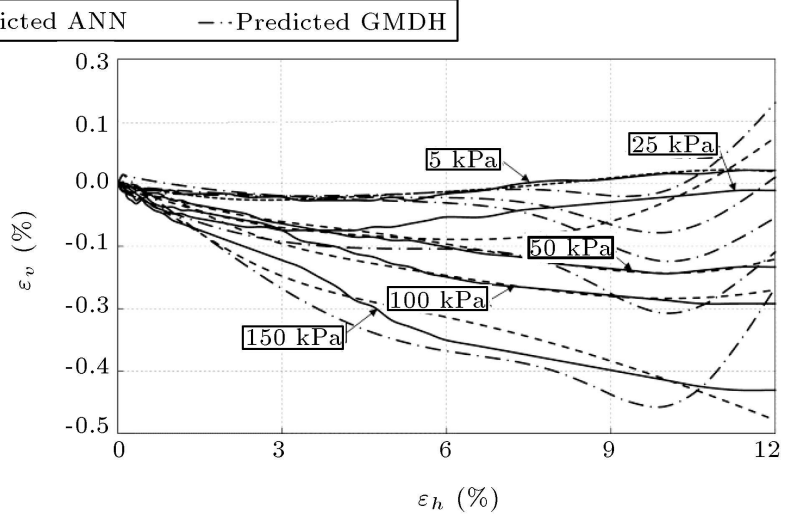

(b)

Figure 6. Direct shear test, ANN and GMDH results for RC2: (a) Shear stress and (b) vertical strain versus horizontal strain.

Table 3. Statistical characteristics of input and output data values.

\begin{tabular}{cccccccc}
\hline Statistical value & $\boldsymbol{C}_{\boldsymbol{u}}$ & $\boldsymbol{C}_{\boldsymbol{c}}$ & $\boldsymbol{D}_{\mathbf{5 0}}(\mathbf{m m})$ & $\boldsymbol{\varepsilon}_{\boldsymbol{h}}(\boldsymbol{\%})$ & $\boldsymbol{\sigma}_{\boldsymbol{n}}(\mathbf{k P a})$ & $\boldsymbol{\varepsilon}_{\boldsymbol{v}}(\boldsymbol{\%})$ & $\boldsymbol{\tau}(\mathbf{k P a})$ \\
\hline Maximum & 5.00 & 1.23 & 19.10 & 18.00 & 150.00 & 1.67 & 114.17 \\
Minimum & 1.61 & 0.89 & 0.28 & 0.00 & 5.00 & -1.88 & 0.00 \\
Average & 2.80 & 1.07 & 5.94 & 5.45 & 66.32 & -0.47 & 28.35 \\
Standard deviation & 1.22 & 0.12 & 7.10 & 4.71 & 52.67 & 0.58 & 27.04 \\
Coefficient of variation & 0.43 & 0.11 & 1.20 & 0.86 & 0.79 & -1.24 & 0.95 \\
\hline
\end{tabular}

natural biological neuron where dendrites in a neuron obtain information from preceding neurons and axons sending the processed information of one neuron to another. Signals through synapses are in charge of providing connections with other cells. An artificial neuron is similar to a biological neuron and has neuron cells, inputs, and targets [35,37]. An artificial neural network comprises two or more layers where a set of neurons exists. By using weighted connections, each layer interrelates with others for creating a network. Input parameter data are then multiplied by the weight values, and their sum with bias forms the input to the net transfer function $(f)$. In an artificial neuron, network inputs include $y_{j}$ in which $j$ is between 1 and $m$ and $m$ is the $m$ th input variable; these network inputs correlate with each other using the net transfer function. A weighted linear combination can be described below:

$$
u=f\left(\sum_{j=1}^{n} w_{j} y_{j}+\theta\right)
$$

where $u$ is the desired output, $w_{j}$ represents weights 


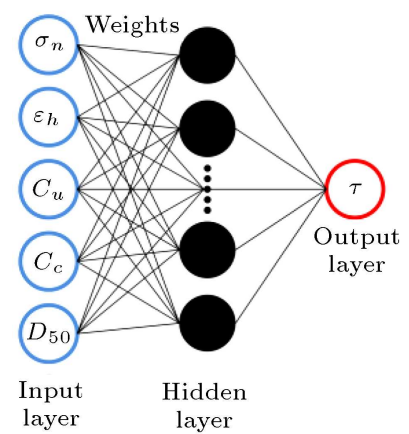

(a)

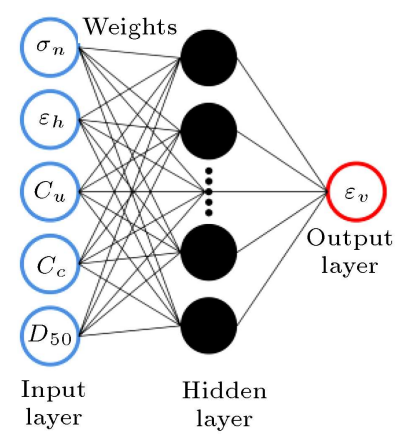

(b)
Figure 7. Developed network architecture: (a) Shear stress and (b) vertical strain versus horizontal strain.

in which $j$ varies between 1 and $m$, and $\theta$ value is called the bias, which is used for the model threshold [37]. Feedforward backpropagation network using the Levenberg -Marquardt algorithm was used in this study. These networks have been proven to be capable of modeling complex engineering problems [35,37-40]. Further details of this type of networks and their performance can be found in [38] and are out of the scope of this paper.

In the Direct Shear Tests (DST), acquired results were used to develop Artificial Neural Networks (ANN) in which input variables are $\sigma_{n}, \varepsilon_{h}, C_{u}, C_{c}, D_{50}$ and outputs include shear stress $(\tau)$ and vertical strain $\left(\varepsilon_{v}\right)$. Thus, two sets of networks have been developed in order to provide a model of shear stress $(\tau)$ and vertical strain $\left(\varepsilon_{v}\right)$ versus horizontal strain $\left(\varepsilon_{h}\right)$. The architecture of networks in terms of input, hidden layer, and the output layer is shown in Figure $7(\mathrm{a})$ and (b) for $\tau$ and $\varepsilon_{v}$, respectively. In this study, the presented artificial neural networks are called 5-n-1, where the first digit is the number of input nodes, $n$ is the number of hidden nodes, and the third digit is the number of output nodes, as shown in Figure 7(a) and (b). Training, testing, and validation processes of the network were performed using neural network toolbox in MATLAB 2014. Moreover, about 60 percent of the whole data were specified randomly for training, 20 percent for validation, and the remaining 20 percent for testing.

\subsubsection{Combinatorial GMDH model development}

Group Method of Data Handling (GMDH) model is an algorithm to find a complex polynomial function that is linear in the parameters. Combinatorial (COMBI) model is a subset of terms of a polynomial function generated from a given set of variables [41,42]. For instance, if a dataset of two input variables $x_{1}$ and $x_{2}$ and an output (target) variable $y$ is modeled, the quadratic polynomial function is presented as in the following, for which the optimization of constants $a_{p}$ where $p \geq 0$ must be performed:

$$
y=a_{0}+a_{1} x_{1}+a_{2} x_{2}+a_{3} x_{1} \cdot x_{2}+a_{4} x_{1}^{2}+a_{5} x_{2}^{2},
$$

The maximum power of the polynomial function is user-defined, and the complexity of the problem may increase in case higher orders are chosen. Combinatorial GMDH selects an optimally-complex model; for instance, $y=a_{0}+a_{3} x_{1} x_{2}$ as a subset of terms of a complete polynomial with the smallest model in testing data. Data preprocessing stage allows applying different operators to variables $x_{1}$ and $x_{2}$ such as an exponent, a sigmoid function, time series lags, and so on. However, the final model will be still linear in the parameters. A full combinatorial search of model components frequently takes too much time; therefore, the search of models can be limited in a way that no more than $n$ terms are included in the model. Models with only 2 terms, for example, allow search among thousands of possible combinations of variables; probably, larger sets might be assembled. At the same time, the full search is not recommended for model spaces with more than 25 polynomials or linear terms. For a linear combination of three input variables, seven different possibilities exist $\left(2^{m}-1\right.$ is the number of possibilities for linear combination, in which $m$ is the number of input variables). Combinatorial GMDH, in general, is a time-consuming algorithm. However, it is capable to provide a closed-form solution that can provide the target in a straightforward manner, if proper parameters, such as the appropriate fitness function, are chosen before running the algorithm. Further information about combinatorial GMDH approach can be found in the references [41,43-45].

\section{Results and discussion}

\subsection{Experimental and computational test results}

Direct Shear Test (DST) results of GR1, GR2, GR3, RC1, and RC2 rubber samples are presented in Figures 2 to 6 . Based on Figures 2(a) to 4(a), it can be inferred that the maximum shear strengths of GR2 and GR3 samples were 5.45 and 54.78 percent more than that of GR1, respectively, in the case of applying $5 \mathrm{kPa}$ normal stress. Moreover, there was an increase of 16.14 and 30.21 percent when the surcharge of $25 \mathrm{kPa}$ was exerted. For higher normal stresses, average growth rates of approximately 9 and 12 percent were observed for GR2 and GR3 rubber samples, respectively. Thus, it can be concluded that the shear responses of GR samples are strongly dependent on the size of grains for which the larger $D_{50}$ leads to higher maximum shear stress for the entire exerted normal stresses. Additionally, for 5 and $25 \mathrm{kPa}$ normal stresses, the maximum shear strength growth is considerably larger, compared to higher normal stress levels. This behavior can also be correlated to the participation of larger 
particles in the shear plane when lower levels of normal stress are applied. However, in higher surcharges, larger grains were contracted and the entire particles were responsible for shear stress bearing in the shear plane and forming the loading skeleton of rubber specimens. The trend is in agreement with what was reported by Kim and Santamarina [46] for large rubber particles. According to Figures 5(a) and 6(a), maximum shear stresses of $\mathrm{RC} 2$ were 47.27 and 32.23 percent more than those of RC1 for 5 and $25 \mathrm{kPa}$ normal stresses, respectively. Moreover, the average growth of approximately 5 percent occurred for 50, 100, and $150 \mathrm{kPa}$ surcharges. The maximum shear strength of RC sets is less than that of GR group, which can be related to the arrangement of the particles. In fact, the relative densities of GR and RC samples were strained to become the same in level. Therefore, in RC samples, which enclosed larger particles, the voids were not distributed all over the shear box and might lead to lower shear strength, particularly in large normal stresses.

Considering Figures 2(b) to 4(b), it can be seen that samples are contracted firstly and, then, expansion behavior is observed for small normal stresses. For larger normal stresses $(50,100$, and $150 \mathrm{kPa}), \mathrm{GR}$ specimens are steeply compressed up to 2.5 percent of horizontal strain, and the compression trend smoothly continues. According to Figures 5(b) and 6(b), dilation behavior is roughly witnessed in $\mathrm{RC}$ samples regardless of the normal applied stress. RC2 sample, which is the largest sample size, is less compressible than any other tested rubber sample. This can be related to the nature of rubber material particles, which are comparatively large and less deformable.

Based on the Mohr-Coulomb failure criterion, shear strength parameters, including internal friction angle $(\varphi)$ and apparent cohesion (c) of the tested samples, were calculated, as presented in Table 4. As can be seen, the values of $\varphi$ and $c$ for GR1 are $2.4^{\circ}$ and $5.42 \mathrm{kPa}$ greater than those for GR2, respectively, and $0.3^{\circ}$ and $3.82 \mathrm{kPa}$ greater than those for GR3 sample, respectively. The value of internal friction angle for RC1 sample is $0.8^{\circ}$ less than that for RC2. However, cohesion intercept of RC2 sample is 3.53 $\mathrm{kPa}$ more than that of $\mathrm{RC} 1$.

\subsection{Optimized network}

The main concern regarding the artificial neural network is to find an optimized network according to the number of neurons existing in the hidden layer for which the maximum regression value or correlation coefficient $(R)$ and minimum Mean Square Error (MSE) occur. By finding the optimized ANN in this research, networks containing 5 to 25 neurons in the hidden layer were modeled for shear stress and vertical strain, separately.

Based on the results presented in Figures 8 and 9 , it can be inferred that the entire networks provide a good approximation, particularly with 13 and 24 neurons for shear stress and vertical strain, respectively. The selected combination as an optimized network is due to the very low values of MSE that are 0.000047965 and 0.00009467 for shear stress and vertical strain ANN models, respectively. Additionally, correlation coefficient $(R)$ values for both of the selected networks are the maximum value between other networks. Figure 10 depicts DST experimental shear stress and vertical strain values versus ANN predicted values. It can be seen that point distributions are close to the ideal fit line that shows maximum fitness and appropriateness of the ANN model. However, other criteria are available for model performance evaluation, which is to be discussed in the following sections.

\subsection{GMDH algorithm results}

Twenty percent of the entire data are randomly put aside for the testing stage in the algorithm, providing more reliable predictions due to the fact that they are not used in the model training and constant optimization. Eqs. (4) and (5) are driven using the combinatorial GMDH method for estimating shear stress $(\tau)$ and vertical strain $\left(\varepsilon_{v}\right)$ after so many trials have occurred. It can be seen that the input parameters form the equations with different orders and combinations with constants.

$$
\begin{aligned}
\tau= & 0.115-\frac{0.022 C_{u}}{C_{c}}+\frac{0.009 \sigma_{n}}{C_{u}}+0.425 \sigma_{n} C_{c} \\
+ & \frac{0.56 \sigma_{n}}{D_{50}}-\frac{0.055 \sigma_{n}}{\varepsilon_{h}}+0.4 \sigma_{n} \varepsilon_{h},
\end{aligned}
$$

Table 4. Summary of rubber grains shear strength parameters.

\begin{tabular}{cccccccc}
\hline \multirow{2}{*}{ Material } & & $\begin{array}{c}\text { Direct shear } \\
\text { test type }\end{array}$ & $\begin{array}{c}\text { Maximum grain } \\
\text { size }(\mathbf{m m})\end{array}$ & $\begin{array}{c}\boldsymbol{\sigma}_{n} \\
(\mathbf{k P a})\end{array}$ & $\begin{array}{c}\boldsymbol{c} \\
(\mathbf{k P a})\end{array}$ & $\begin{array}{c}\boldsymbol{\varphi} \\
(\mathbf{D e g r e e})\end{array}$ & $\begin{array}{c}\text { Failure criterion } \\
\text { point }\end{array}$ \\
\hline \multirow{2}{*}{$\begin{array}{c}\text { Granulated } \\
\text { Rubber (GR) }\end{array}$} & GR1 & Small scale & 1.18 & & 11.02 & 34.6 & $15 \%$ of horizontal strain. \\
& GR2 & Small scale & 4.75 & 5.60 & 32.2 & \\
& GR3 & Small scale & 4.75 & $5-150$ & 7.20 & 34.3 & \\
Rubber & RC1 & Large scale & 15 & & & & \\
Chips (RC) & RC2 & Large scale & 50 & 8.69 & 31.3 & $12 \%$ of horizontal strain. \\
\hline
\end{tabular}




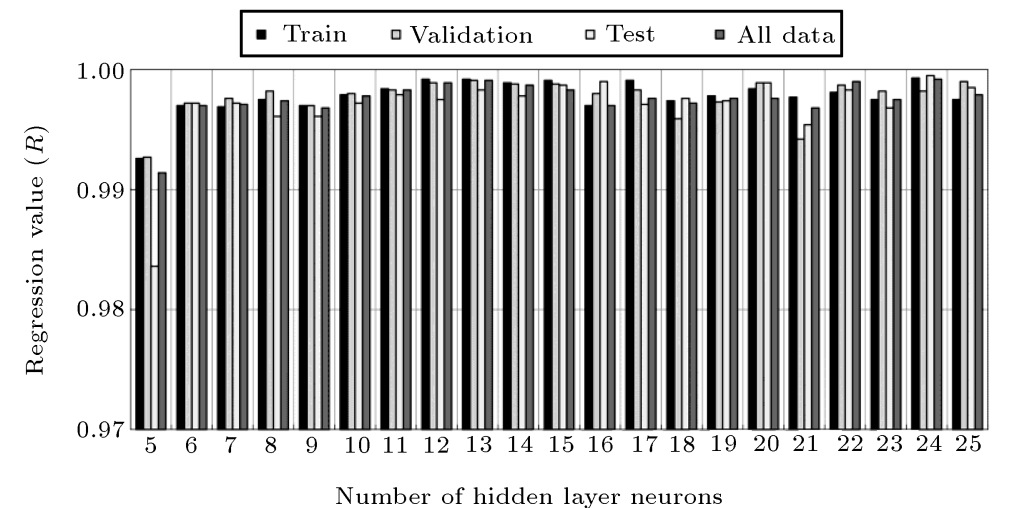

(a)

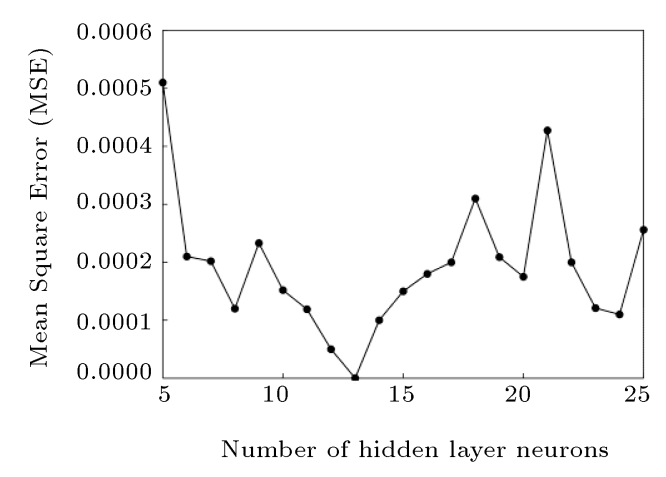

(b)

Figure 8. Shear stress: (a) Regression value $(R)$ and (b) Mean Square Error (MSE) for ANNs with different neurons in the hidden layer.

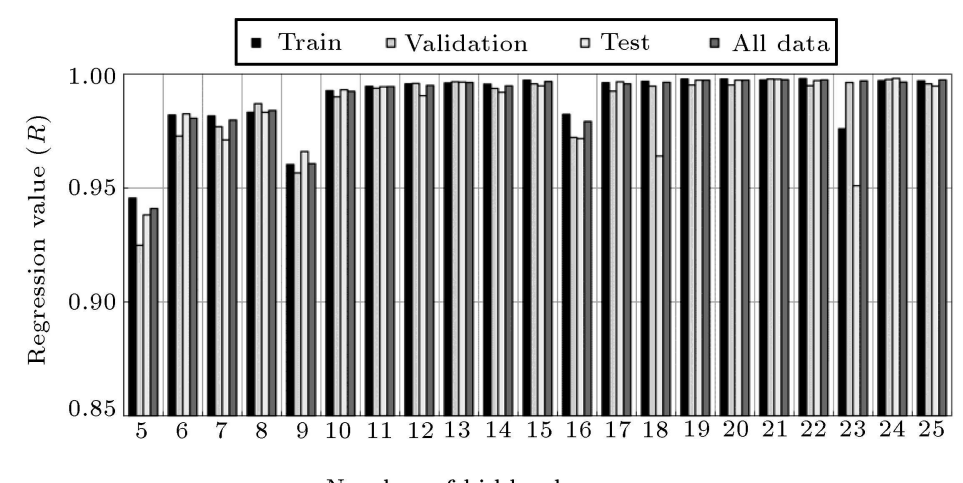

Number of hidden layer neurons

(a)

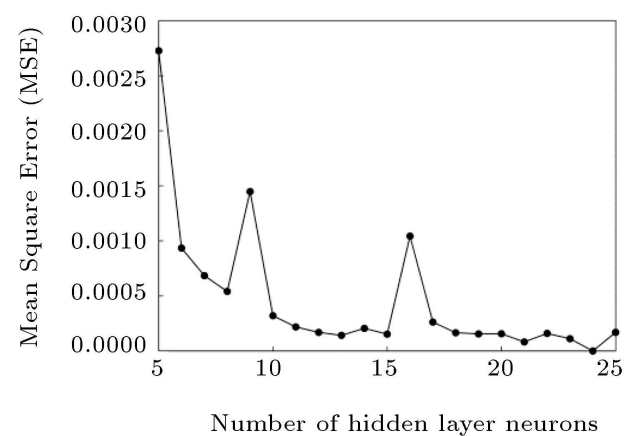

(b)

Figure 9. Vertical strain: (a) Regression value $(R)$ and (b) Mean Square Error (MSE) for ANNs with different neurons in the hidden layer.

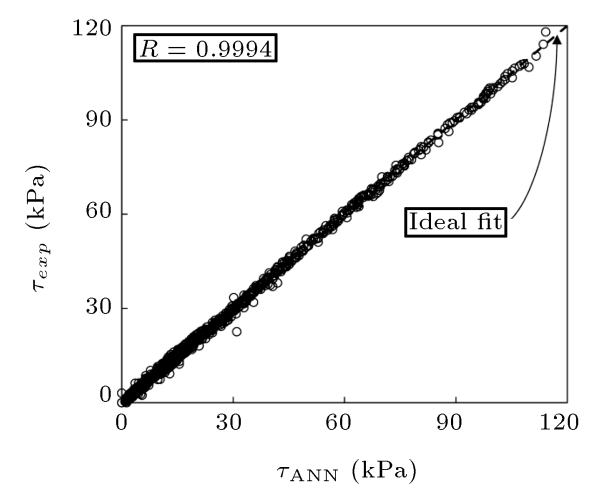

(a)

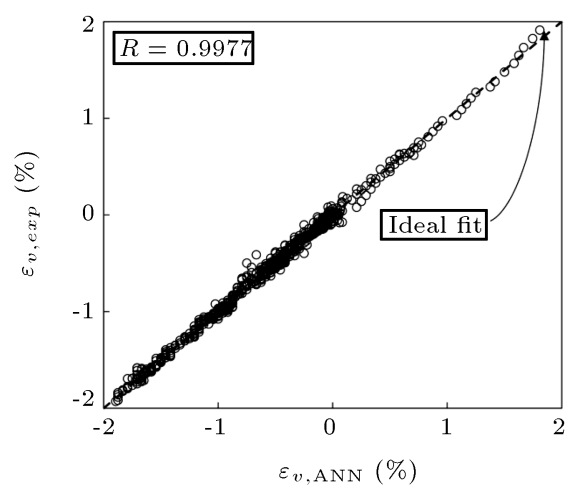

(b)

Figure 10. (a) Experimental shear stress and (b) Experimental vertical strain versus the ANN model predicted values.

$\varepsilon_{v}=0.53$

$$
\begin{aligned}
& -\frac{0.0017 \varepsilon_{h}+0.00035 \varepsilon_{h}{ }^{2}+0.002 \varepsilon_{h} \sigma_{n}+0.0007 \sigma_{n}{ }^{2}}{C_{u}{ }^{2} D_{50}} \\
& +\frac{0.0002 \varepsilon_{h}}{C_{u}{ }^{2} D_{50} \sigma_{n}}-\frac{0.099 \sigma_{n}-0.105 C_{u} \sigma_{n}{ }^{3}}{D_{50}}+\frac{0.0028 \sigma_{n} C_{u}}{C_{c}{ }^{2} \varepsilon_{h}} \text { (5) }
\end{aligned}
$$

It must be noted that these equations are developed based on the normalized and scaled input data whose outcomes are the normalized and scaled target values. Moreover, in order to show the suitability of the developed models, measured values versus GMDH predicted ones are depicted in Figure 11 for both of the shear stress and vertical strain target parameters. It can be seen that the deviation of plotted points 


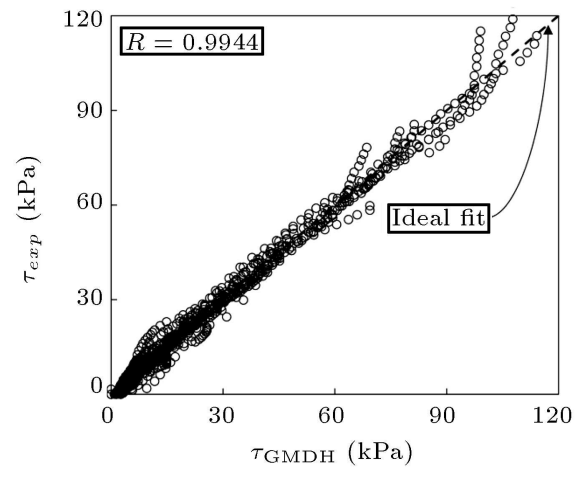

(a)

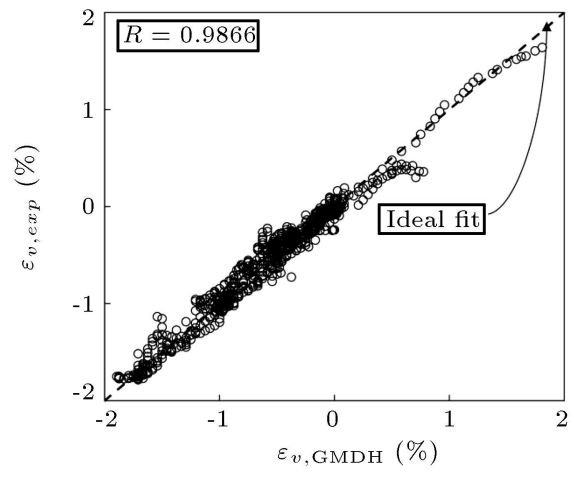

(b)

Figure 11. (a) Experimental shear stress and (b) experimental vertical strain versus GMDH model predicted values.

from the ideal fit line is not as suitable as is the case with the ANN model. However, the closedform formulation is an advantage that outperforms the former model.

\subsection{Performance evaluation of developed models}

The performance of the developed models can be evaluated using some predefined expressions as yardsticks to show the accuracy of the models. The following criteria were suggested by Smith (1986) for assessing the fitness of a model [47]:

- A strong correlation exists between the predicted and target values when $|R|>0.8$;

- A correlation exists between the predicted and target values when $0.2<|R|<0.8$;

- Existing correlation between the predicted and target values is weak when $|R|<0.2$.

In any case, there should be only tolerable minimum error values, and an acceptable degree of accuracy can be achieved using the model with high $R$ and low MSE values or other introduced criteria. The favorable performance of the model in both the training and testing datasets indicates that the model has achieved both accurate predictive capability and sufficient generalization. Previously, researchers have suggested that the minimum value for one of the slopes of the regression lines ( $k$ or $k^{\prime}$ ) through the origin should be close to unity, wherein $k$ is the slope of the regression line in a plot of actual data $\left(h_{i}\right)$ against predicted values $\left(t_{i}\right)$, and $k^{\prime}$ is the slope of the regression line in a plot of predicted values against actual values $[48,49]$. Either the squared correlation coefficient (through the origin) between predicted and experimental values $\left(\rho^{2}\right)$, or the coefficient between experimental and predicted values $\left(\rho^{\prime 2}\right)$ should be close to 1 . The validation criteria and associated results obtained by the models are presented in Table 5, showing that the developed models satisfy the required criteria. Additionally, the achieved error benchmarks, Mean Absolute Error (MAE), Mean Squared Error (MSE), and Root Mean Squared Error (RMSE) are included in Table 5. It can be inferred that the error value in the ANN model is lower than that in GMDH as well as regression values $(R)$. However, there is a strong correlation between the predicted and measured values for both of the ANN and GMDH models.

Table 5. Different regression values for the model performance evaluation.

\begin{tabular}{|c|c|c|c|c|c|c|c|c|c|}
\hline Method & target & $k$ & $k^{\prime}$ & $\rho^{2}$ & $\rho^{\prime 2}$ & $R^{\mathrm{a}}$ & $\mathbf{M A E}^{\mathrm{b}}$ & MSE $^{c}$ & RMSE $^{\mathrm{d}}$ \\
\hline \multirow{2}{*}{ ANN } & $\varepsilon_{v}$ & 0.9944 & 1.0028 & 0.9888 & 1.0056 & 0.9977 & 0.0278 & 0.0016 & 0.0401 \\
\hline & $\tau$ & 0.9979 & 1.0016 & 0.9958 & 1.0032 & 0.9994 & 0.6431 & 0.8452 & 0.9194 \\
\hline \multirow{2}{*}{ GMDH } & $\varepsilon_{v}$ & 0.9743 & 1.0094 & 0.9493 & 1.0189 & 0.9867 & 0. 0710 & 0.0095 & 0.0974 \\
\hline & $\tau$ & 0.9953 & 0.9992 & 0.9906 & 0.9984 & 0.9942 & 2.0774 & 8.4918 & 2.9141 \\
\hline
\end{tabular}

It should be noted that $N$ is the number of data points presented to the model; $X_{i}$ and $Y_{i}$ are the measured and model predicted outputs, respectively. $\bar{X}$ and $\bar{Y}$ are the mean values of the experimentally measured and model predicted outputs, respectively. 
By using the GMDH and ANN developed models, shear stress and vertical strain changes with horizontal strain are depicted in Figures 2 to 6 as well as measured values. It can be seen that both methods estimated shear stress changes for different applied normal stresses according to different sizes of the grains. However, compared to the GMDH model, the ANN model for vertical strain provided more accurate values for the entire samples.

\section{Conclusion}

Small and large direct shear tests were performed on five different sets of rubber wastes, named granulated rubber (GR1, GR2, and GR3) and rubber chips (RC1 and RC2). Granulated rubber sets, GR1 and GR3, include particles with diameters ranging from 0.075 to $1.18 \mathrm{~mm}$ and 0.425 to $4.75 \mathrm{~mm}$, respectively; GR2, which is widely distributed between the other two groups, includes grains with diameters ranging from 0.075 to $4.75 \mathrm{~mm}$. Rubber chips samples, $\mathrm{RC} 1$ and $\mathrm{RC} 2$, consist of particles with diameters varying from 0.425 to $25 \mathrm{~mm}$ and 4.69 to $50 \mathrm{~mm}$. RC1 and GR2 are widely extended between other rubber samples. The results show that grain size can make some changes in shear strength. Based on DST results, it can be stated that GR group tends to show larger shear strength due to its consistent and more uniform matrix, resulting from grains arrangement in the shear box. Additionally, the load-bearing skeleton is formed in the GR group, which is not the same case in $\mathrm{RC}$ specimens.

Experimental data were used to introduce an Artificial Neural Network (ANN) and combinatorial Group Method of Data Handling (GMDH) in order to simulate shear stress and vertical strain changes along with horizontal strain. Input variables for these models are $\sigma_{n}, \varepsilon_{h}, C_{u}, C_{c}$, and $D_{50}$ that, finally, lead to achieving shear stress and vertical strain responses of the rubber materials. Optimized network architectures are 5-13-1 and 5-24-1, which can perfectly simulate the shear stress and vertical strain, respectively.

A GMDH approach using combinatorial algorithm was implemented for developing explicit equations, which can capture shear stress and vertical strain responses. The ANN and GMDH models' performances have been checked based on different criteria such as correlation coefficient $(R)$, and the error values were relatively small for the introduced models. The presented closed-form equation based on the GMDH gives reliable estimations for shear strength and vertical strain, as last checked based on model verification benchmarks.

\section{References}

1. Rubber Manufacturers Association-(RMA), 2015 U.S.
Scrap Tire Management Summary, Washington DC, United States of America (2016).

2. World Business Council for Sustainable Development (WBCSD), Managing End-of-Life Tires (2008).

3. Sienkiewicz, M., Janik, H., Borzȩdowska-Labuda, K., and Kucińska-Lipka, J. "Environmentally friendly polymer-rubber composites obtained from waste tyres: A review", Journal of Cleaner Production, 147, pp. 560-571 (2017).

4. Humphrey, Dana N., Thomas C., Sandford, Michelle M., Cribbs, and William P. Manion "Shear strength and compressibility of tire chips for use as retaining wall backfill", Transportation Research Record 1422 (1993).

5. Bosscher, P.J., Edil, T.B., and Kuraoka, S. "Design of highway embankments using tire chips", Journal of Geotechnical and Geoenvironmental Engineering, 123(4), pp. 295-304 (1997).

6. Yang, S., Lohnes, R.A., and Kjartanson, B.H. "Mechanical properties of shredded tires", Geotechnical Testing Journal, 25(1), pp. 44-52 (2002).

7. Tafreshi, S.N.M., Mehrjardi, G.T., and Dawson, A.R. "Buried pipes in rubber-soil backfilled trenches under cyclic loading", Journal of Geotechnical and Geoenvironmental Engineering, 138(11), pp. 1346-1356 (2012).

8. Warith, M.A. and Rao, S.M. "Predicting the compressibility behaviour of tire shred samples for landfill applications", Waste Management, 26(3), pp. 268-276 (2006).

9. Ahmed, I. and Lovell, C.W. "Use of rubber tires in highway construction", Utilization of Waste Materials in Civil Engineering Construction (ASCE), New York, United States, pp. 166-181 (1992).

https://cedb.asce.org/CEDBsearch/record.jsp? dockey $=0078934$

10. Meles, D., Bayat, A., Hussien Shafiee, M., Nassiri, S., and Gul, M. "Investigation of tire derived aggregate as a fill material for highway embankment", International Journal of Geotechnical Engineering, 8(2), pp. 182-190 (2014).

11. Yoon, S., Prezzi, M., Siddiki, N.Z., and Kim, B. "Construction of a test embankment using a sand-tire shred mixture as fill material", Waste Management, 26(9), pp. 1033-1044 (2006).

12. ASTM D6270, Standard Practice for Use of Scrap Tires in Civil Engineering Applications, Annual Book of ASTM Standards (2014).

13. Edinçliler, A., Baykal, G., and Saygili, A. "Influence of different processing techniques on the mechanical properties of used tires in embankment construction", Waste Management, 30(6), pp. 1073-1080 (2010).

14. Zornberg, J.G., Cabral, A.R., and Viratjandr, C. "Behaviour of tire shred - sand mixtures", Canadian Geotechnical Journal, 41(2), pp. 227-241 (2004).

15. Neaz Sheikh, M., Mashiri, M.S., Vinod, J.S., and Tsang, H. "Shear and compressibility behavior of sandtire crumb mixtures", Journal of Materials in Civil Engineering, 25(10), pp. 1366-1374 (2013). 
16. Lee, J.H., Salgado, R., Bernal, A., and Lovell, C.W. "Shredded tires and rubber-sand as lightweight backfill", Journal of Geotechnical \& Geoenvironmental Engineering, 125(2), pp. 132-141 (1999).

17. Edincliler, A., Cabalar, A.F., Cagatay, A., and Cevik, A. "Triaxial compression behavior of sand and tire wastes using neural networks", Neural Computing and Applications, 21(3), pp. 441-452 (2012).

18. Cabalar, A.F. "Direct shear tests on waste tires-sand mixtures", Geotechnical and Geological Engineering, 29(4), pp. 411-418 (2010).

19. Balachowsky, L. and Gotteland, P. "Characteristics of tyre chips-sand mixtures from triaxial tests", Archives of Hydro-Engineering and Environmental Mechanics, 54(1), pp. 25-36 (2007).

20. Foose, G.J.G., Benson, C.H., and Bosscher, P.J. "Sand reinforced with shredded waste tire", Journal of Materials in Civil Engineering, 122(9), pp. 760-767 (1996).

21. Reddy, K. and Marella, A. "Properties of different size scrap tire shreds: Implications on using as drainage material in landfill cover systems", Proceedings of the rth International Conference on Solid Waste Technology and Management, Philadelphia, USA, pp. 1-19 (2001).

22. Reddy, S.B., Krishna, A.M., and Reddy, K.R. "Sustainable utilization of scrap tire derived geomaterials for geotechnical applications", Indian Geotechnical Journal, 48(2), pp. 251-266 (2018).

23. Bali Reddy, S., Pradeep Kumar, D., and Murali Krishna, A. "Evaluation of the optimum mixing ratio of a sand-tire chips mixture for geoengineering applications", Journal of Materials in Civil Engineering, 28(2), p. 6015007 (2016).

24. Reddy, S.B. and Krishna, A.M. "Recycled tire chips mixed with sand as lightweight backfill material in retaining wall applications: An experimental investigation", International Journal of Geosynthetics and Ground Engineering, Springer International Publishing, 1(4), p. 31 (2015).

25. Jamshidi Chenari, R., Fatahi, B., Akhavan Maroufi, M.A., and Alaie, R. "An experimental and numerical investigation into the compressibility and settlement of sand mixed with TDA", Geotechnical and Geological Engineering, 35(5), pp. 2401-2420 (2017).

26. Reddy, S.B. and Krishna, A.M. "Sand-tire chip mixtures for sustainable geoengineering applications", In Sustainability Issues in Civil Engineering, Singapore, pp. 223-241 (2017).

27. Rao, G.V. and Dutta, R.K. "Compressibility and strength behaviour of sand-tyre chip mixtures", Geotechnical and Geological Engineering, 24(3), pp. 711-724 (2006).

28. Gebhardt, M.A. "Shear strength of shredded tires as applied to the design and construction of a shredded tire stream crossing", MS Thesis, Iowa State University, USA (1997).
29. Kjartanson, B.H., Lohnes, R.A., Yang, S., Kerr, M.L., Zimmerman, P.S., and Gebhardt, M.A. "Use of waste tires in civil and environmental construction", Final Report, Iowa Department of Natural Resources Landfill Alternatives Financial Assistance Program (1993).

30. Fox, P.J., Thielmann, S.S., Sanders, M.J., Latham, C., Ghaaowd, I., and McCartney, J.S. "Large scale combination direct shear/simple shear device for tire-derived aggregate", Geotechnical Testing Journal, 41(2), p. 20160245 (2018).

31. Anbazhagan, P., Manohar, D.R., and Rohit, D. "Influence of size of granulated rubber and tyre chips on the shear strength characteristics of sand-rubber mix", Geomechanics and Geoengineering, 12(4), pp. 266-278 (2016).

32. ASTM D2487, "Standard practice for classification of soils for engineering purposes (unified soil classification system)", Annual Book of ASTM Standards (2011).

33. ASTM D3080, "Standard test method for direct shear test of soils under consolidated drained conditions", Annual Book of ASTM Standards (2003).

34. Shahin, M.A., Maier, H.R., and Jaksa, M.B. "Predicting settlement of shallow foundations using neural networks", Journal of Geotechnical and Geoenvironmental Engineering, 128(9), pp. 785-793 (2002).

35. Ahmadi, M., Naderpour, H., and Kheyroddin, A. "ANN model for predicting the compressive strength of circular steel-confined concrete", International Journal of Civil Engineering, 15(2), pp. 213-221 (2017).

36. Ranasinghe, R.A.T.M., Jaksa, M.B., Kuo, Y.L., and Pooya Nejad, F. "Application of artificial neural networks for predicting the impact of rolling dynamic compaction using dynamic cone penetrometer test results", Journal of Rock Mechanics and Geotechnical Engineering, 9(2), pp. 340-349 (2017).

37. Ahmadi, M., Naderpour, H., and Kheyroddin, A. "Utilization of artificial neural networks to prediction of the capacity of CCFT short columns subject to short term axial load", Archives of Civil and Mechanical Engineering, Politechnika Wroclawska, 14(3), pp. 510517 (2014).

38. Naderpour, H., Kheyroddin, A., and Amiri, G.G. "Prediction of FRP-confined compressive strength of concrete using artificial neural networks", Composite Structures, 92(12), pp. 2817-2829 (2010).

39. Javdanian, H., Jafarian, Y., and Haddad, A. "Predicting damping ratio of fine-grained soils using soft computing methodology", Arabian Journal of Geosciences, 8(6), pp. 3959-3969 (2015).

40. Jafarian, Y., Javdanian, H., and Haddad, A. "Predictive model for normalized shear modulus of cohesive soils", Acta Geodynamica et Geomaterialia, 11(1), pp. 89-100 (2013).

41. Madala, H.R. and Ivakhnenko, A.G., Inductive Learning Algorithms for Complex Systems Modeling, CRC Press, Boca Raton (1994). 
42. Azimi, A. "GMDH-network to estimate the punching capacity of FRP-RC slabs", Journal of Soft Computing in Civil Engineering, 1(1), pp. 86-92 (2017).

43. Ivakhnenko, A.G. "Polynomial theory of complex systems", IEEE Transactions on Systems, Man, and Cybernetics, 1(4), pp. 364-378 (1971).

44. Farlow, S.J., Self-Organizing Methods in Modeling: GMDH Type Algorithms, CRC Press (1984).

45. Ivakhnenko, A.G., Savchenko, E.A., and Ivakhnenko, G.A. "GMDH algorithm for optimal model choice by the external error criterion with the extension of definition by model bias and its applications to the committees and neural networks", Pattern Recogn. Image Anal., 12(4), pp. 347-353 (2002).

46. Kim, H.-K. and Santamarina, J.C. "Sand-rubber mixtures (large rubber chips)", Canadian Geotechnical Journal, 45(10), pp. 1457-1466 (2008).

47. Smith, G.N., Probability and Statistics in Civil Engineering, Collins Professional and Technical Books (1986).

48. Alavi, A.H., Ameri, M., Gandomi, A.H., and Mirzahosseini, M.R. "Formulation of flow number of asphalt mixes using a hybrid computational method", Construction and Building Materials, 25(3), pp. 1338-1355 (2011).

49. Golbraikh, A. and Tropsha, A. "Beware of q2!", Journal of Molecular Graphics and Modelling, 20(4), pp. 269-276 (2002).

\section{Biographies}

Danial Rezazadeh Eidgahee is currently a $\mathrm{PhD}$ candidate in Geotechnical Engineering, Semnan University, Semnan, Iran. He obtained his MSc degree in 2013 from the Ferdowsi University of Mashhad in the area of Discrete Element Modeling (DEM) of granular materials. His $\mathrm{PhD}$ researches include experimental and numerical investigations on the geomaterials' mechanical behavior. He is interested in applications of soft computing approaches and probabilistic studies in the field of geotechnical and foundation engineering.

Abdolhosein Haddad obtained an MSc degree from Iran University of Science \& Technology, Tehran and a PhD from Engineering School of Shiraz University, Shiraz, Iran. He is an Associate Professor of Geotechnical Engineering and the Head of the Geotechnical Engineering Department at the Semnan University, Semnan, Iran. He has been involved in geotechnical research, consulting and education for more than 17 years. He has authored or co-authored 3 books in geotechnical engineering and more than 50 scientific papers. Moreover, he is a member of the editorial board of the Journal of Rehabilitation in Civil Engineering (JRCE), published by Semnan University Press.

Hosein Naderpour received his $\mathrm{PhD}$ degree with high honors in Structural Engineering. He then joined Semnan University where he is presently an Associate Professor of Structural Engineering. Since joining the faculty of Civil Engineering at Semnan University, he has taught a variety of undergraduate and graduate courses in the areas of structural engineering, numerical methods, mechanics of materials, structural stability, concrete structures, structural reliability, and soft computing. Dr. Naderpour is the author of 70 papers published in journals and about 150 papers presented at national and international conferences. He has given several speeches in Switzerland, China, Australia, South Korea, Romania, Turkey, Canada, Hong Kong, Belgium, Portugal, Spain, Japan, Germany, Italy, Czech Republic, and France. He is currently a chief member of Iranian Earthquake Engineering Association, Iran Concrete Institute (ICI), Iranian Society for Light Steel Framing (LSF), Iran's National Elites Foundation, Safe School Committee, Organization for Development, Renovation and Equipping Schools of Iran (DRES). His major research interests include the application of soft computing in structural engineering, seismic resilience, structural reliability, structural optimization, and damage detection of structures. 